\title{
Immunohistochemical analysis of beta-catenin expression: a probable prognostic marker and potential therapeutic target in renal cell carcinoma
}

\author{
Ayan Kundu ${ }^{1}$, Anway Sen ${ }^{1}$, Shouvik Choudhury ${ }^{2}$, \\ Tapan Kumar Mandal ${ }^{3}$, Debasish Guha ${ }^{1}$, Sandeep Lahiry ${ }^{4}$
}

1) Department of Pathology, NRS Medical College \& Hospital, Kolkata, India

2) Department of Pharmacology, Burdwan Medical College, Burdwan, India

3) Department of Urology, NRS Medical College \& Hospital, Kolkata, India

4) Pharmacology, Independent Scholar, Kolkata, India

DOI: $10.15386 / \mathrm{mpr}-1767$

Manuscript received: 08.06.2020

Received in revised form: 31.07 .2020

Accepted: 07.09.2020

Address for correspondence:

86drak@gmail.com

This work is licensed under a Creative Commons Attribution-NonCommercialNoDerivatives 4.0 International License

\begin{abstract}
Background and aims. Renal cell carcinoma (RCC) seems to be the most aggressive type of genitourinary neoplasm. Down regulation of normal beta-catenin expression contributes to development of RCC, reflecting the role of beta-catenin/ Wnt signaling pathway in pathogenesis. This study aims to evaluate the significance of beta-catenin expression and its correlation with the prognostic parameters.
\end{abstract}

Methods. A cross-sectional observational study was carried out in a tertiary care center on 58 RCC cases using variables like histological grade and type, tumor stage, necrosis. Formalin fixed, paraffin-embedded blocks were evaluated for betacatenin expression by immunohistochemistry using scoring system. Data were analyzed by mean $\pm \mathrm{SD}, \chi 2$ test, Pearson's correlation test.

Results. Membranous score (MS) had a strong negative correlation with tumor stage $(\mathrm{r}=-0.407, \mathrm{p}=0.044)$ and grade $(\mathrm{r}=-0.787, \mathrm{p}=<0.001)$. Mean membranous score difference between low (Stage 1 and 2) vs. high stage (Stage 3 and 4) and low (Grade 1 and 2) vs. high grade (Grade 3 and 4) was statistically significant $(\mathrm{p}<0.001)$. Cytoplasmic score (CS) had positive correlation with tumor stage $(r=0.586 ; p=0.002)$. No significant correlation was evident between cytoplasmic scores and tumor grade, however the mean cytoplasmic score difference between low grade vs. high grade was statistically significant $(\mathrm{p}<0.001)$.

Conclusion. Beta-catenin may play a crucial role in the pathogenesis of RCC and has a positive correlation with the biological behavior of this tumor. The important role of beta-catenin as a prognostic parameter and probably a critical evaluator of targeted chemotherapy cannot be overemphasized.

Keywords: renal cell carcinoma, neoplasm, beta-catenin, immunohistochemistry, chemotherapy

\section{Background and aims}

Kidney cancer has been identified as the twelfth most common cancer in the world, with 338,000 new cases diagnosed in 2012 [1]. Renal cell carcinoma (RCC), the most common kidney cancer, accounts for approximately $80-90 \%$ of all primary kidney neoplasms. It is a very aggressive type of genitourinary cancer due to its refractoriness to current treatment regimens, including chemotherapy and radiotherapy [2]. According to GLOBOCAN 2012, in
India 9658 new cases of kidney cancer were diagnosed, while 5973 deaths were reported in the same calendar year [1]. Survival at five years is $>90 \%$ for stage I, and $20-30 \%$ for stage IV, which indicates the importance of stage as prognostic factor [3].

The current treatment algorithm comprises active surveillance for small incidental masses in the elderly and comorbid patients, surgical resection for curative resectable masses and systemic therapy with or without cytoreductive 
surgery in patients with metastatic disease [4]. Common therapeutic regimes include tyrosine kinase inhibitors, antivascular endothelial growth factors, and monoclonal antibodies. As of now, limited efficacy has been reported for these drugs [5], and therefore more potent compounds targeting specific signaling pathways of RCC pathogenesis are required to improve the high rate of refractoriness [6].

To anticipate the clinical outcome of different RCC patients is not always possible with classic prognostic factors, staging and grading, which are primarily used to assess cancer prognosis [7,8]. Appropriate prognostic value may help in patient counseling and also in treatment with follow up [8].

Renal carcinogenesis involves the intervention of numerous signaling pathways. Multiple research reports bring solid evidence for the implication of Wnt/beta-catenin, $\mathrm{PI} 3 \mathrm{~K} / \mathrm{AKT} / \mathrm{mTOR}$ (phosphatidylinositol 3-kinases/ protein kinase $\mathrm{B} /$ mammalian target of rapamycin), HGF/c-Met (hepatocyte growth factor/c-mesenchymal epithelial transition factor), and MAPK (mitogen-activated protein kinase) pathways, by alterations in one or more components of their structure $[9,10]$. Among all these beta-catenin signaling and targeted genes are known to actively participate in different biological processes during embryonic development and RCC [11].

Beta-catenin is both a structural component of cellcell contact sites and a signaling protein that activates the Wnt survival pathway. Wnt, the mammalian homologue, is a family of secreted glycoproteins that control cell proliferation, differentiation, migration and survival. Betacatenin activates target genes such as the MYC (v-myc avian myelocytomatosis viral oncogene homolog) oncogene [12]. MYC depicts copy number amplification in a subset of primary clear cell RCC [13] and papillary RCC [14]. Loss of VHL results in reduced levels of Jade- 1 and consequent increased levels of beta-catenin, providing one mechanism by which VHL loss promotes renal tumorigenesis. MET phosphorylation also induces tyrosine phosphorylation of beta-catenin causing beta-catenin dissociation from E-cadherin followed by nuclear translocation of betacatenin and transcription activation [15]. VHL expression in RCC cells suppresses HGF (Hepatocyte Growth Factor) stimulated beta -catenin signaling and thus loss of VHL in RCC could validate HGF-driven oncogenic betacatenin signaling [16]. Downregulation of normal betacatenin expression, contributes to the malignant character and tumor progression in RCC, shows the role of betacatenin/wnt signaling pathway in RCC. Aberrant staining correlated with an advanced tumor grade and stage [17]. Cytoplasmic beta-catenin corresponds with poor prognosis and reduced survival in RCC [18]. Decreased membranous and increased cytoplasmic expression is also individually related with adverse histopathological features [19].

In this scenario, an institutional based cross sectional observational study was done among the different types of RCC cases with the purpose to assess the beta-catenin expression and to study the possibility of a correlation between histological grade, stage and other prognostic parameters of RCC by immunohistochemistry.

\section{Methods}

This was a cross-sectional observational study conducted in the Department of Pathology in collaboration with Department of Urology of Nil Ratan Sircar medical college and hospital, Kolkata, from February 2016 to January 2017. The work was initiated after obtaining ethical clearance from Institutional Ethical Committee and informed consent from the study population. Study group included 58 cases of histologically diagnosed RCC, subjected to nephrectomy. Data were collected using a pre-designed, pretested semi-structured schedule on dependent variables like beta-catenin expression and independent variables like histological grade, type, stage and other prognostic parameters.

\section{Histopathology}

Tissue slices were taken from different areas of the tumoral properly fixed nephrectomy specimen and processed. Sections (4-5 microns) were stained with routine hematoxylin-eosin stain for histopathological examination. After histological confirmation of the diagnosis, the following parameters were analyzed: histological type, tumor grade (WHO/ International Society of Urological Pathology (ISUP) grading system], lymphovascular and perineural invasion, nodal involvement, necrosis, sarcomatoid or rhabdoid differentiation, staging (American Joint Committee on Cancer 2010).

\section{Immunohistochemistry (IHC)}

For IHC staining, $3 \mu \mathrm{m}$ thick sections from formalin fixed paraffin embedded tissues were taken on poly L Lysine coated slides. IHC was done manually using rabbit monoclonal beta-catenin antibody. Normal colorectal tissue was taken as control for beta-catenin immunohistochemistry. The criterion for a positive immune reaction (in control) was brown membranous staining. Positive findings were evaluated in four fields (1000 cells) under a light microscope at $400 \mathrm{X}$ magnification, without knowledge of the clinical outcome.

\section{Scoring of immunohistochemistry}

The staining intensity was scored as follows: $0=$ no expression, $1+=$ weak expression, $2+=$ moderate expression and $3+=$ strong expression. The final score was depicted as IHC score by multiplying the percentage of positive cells with the staining intensity according to Mauri et al [20]. Nuclear $\beta$-catenin expression was evaluated as either present or absent [18].

\section{Statistical analysis}

Data was entered in MS excel. For descriptive purposes mean $\pm \mathrm{SD}$, range and percentage were used while for testing the relationship between variables chi- 
square $(\chi 2)$ test and Pearson's correlation test was used using SPSS Version 20.0. Armonk, NY: IBM Corp. and GraphPad Prism version 7 La Jolla California USA. Significance level was considered at $\mathrm{p}$ value $<0.05$.

\section{Results}

A total of 58 cases were included: Clear cell RCC (CCRCC) [n=44], Papillary RCC (PRCC) [n=8], Chromophobe RCC (ChRCC) [n=4], Mucinous and Tubular Spindle Cell Carcinoma (MTSCC) [n=1] and Multilocular cystic Renal Neoplasm Of Low Malignant Potential (MRNLMP) [n=1]. According to WHO/ISUP grading system, grade 1, 2 and 3 share equal number of cases $(26 \%) .14 \%$ cases showed sarcomatoid differentiation whereas $7 \%$ cases showed rhabdoid differentiation. Among the 58 cases $32(55.2 \%)$ showed microscopic evidence of lymphovascular invasion, and $15(25.9 \%)$ presented with microscopic evidence of perineural invasion. There were $43 \%$ cases stage I, $12 \%$ cases stage II, $41 \%$ stage III and $4 \%$ stage IV disease. The clinical and pathological characteristics of the study population are shown in table I. Different types of RCC showed different patterns of beta-catenin expression. In clear cell RCC, low grade and stage cases showed predominant membranous expression whereas high grade and stage cases showed predominantly cytoplasmic expression (Figure 1A,B,C and D).
Table I. Clinicopathological profile of renal cell carcinoma cases $(\mathrm{n}=58)$.

$\begin{array}{llcc}\text { Clinicopathological parameters } & \text { Number (\%) } \\ \text { Age in years } & <39 & 6(10.5) \\ & 40-59 & 39(67.24) \\ \text { Sex } & >60 & 13(22.41) \\ & \text { Male } & 42(72.4) \\ & \text { Female } & 16(27.6) \\ \text { Histological type } & \text { CCRCC. } & 44(75.9) \\ & \text { PRCC } & 8(13.8) \\ & \text { ChRCC } & 4(6.9) \\ \text { Histological grade } & \text { MRCC } & 1(1.7) \\ & \text { Low grade } & 1 & 1(1.7) \\ & & 15(25.9) \\ \text { Stage } & \text { High grade } & 3 & 15(25.9) \\ & & 15(25.9) \\ & \text { Low stage } & \text { I } & 13(22.4) \\ \text { LVSI } & \text { II } & 25(43.1) \\ & \text { High stage } & \text { III } & 7(12.1) \\ \text { PNI } & \text { Found } & 24(41.4) \\ & \text { Not found } & & 2(3.4) \\ \text { Necrosis } & \text { Found } & 32(55.2) \\ \text { Sarcomatoid } & \text { Not found } & 26(44.8) \\ \text { Differentiation } & \text { Present } & 15(25.9) \\ \text { Rhabdoid } & \text { Absent } & 43(74.1) \\ \text { Differentiation } & \text { Present } & 34(58.6) \\ & \text { Not found } & 24(41.4) \\ & \text { Present } & 8(13.8) \\ & \text { Not found } & 50(86.2) \\ & & 4(6.9) \\ & & 54(93.1) \\ & & \end{array}$
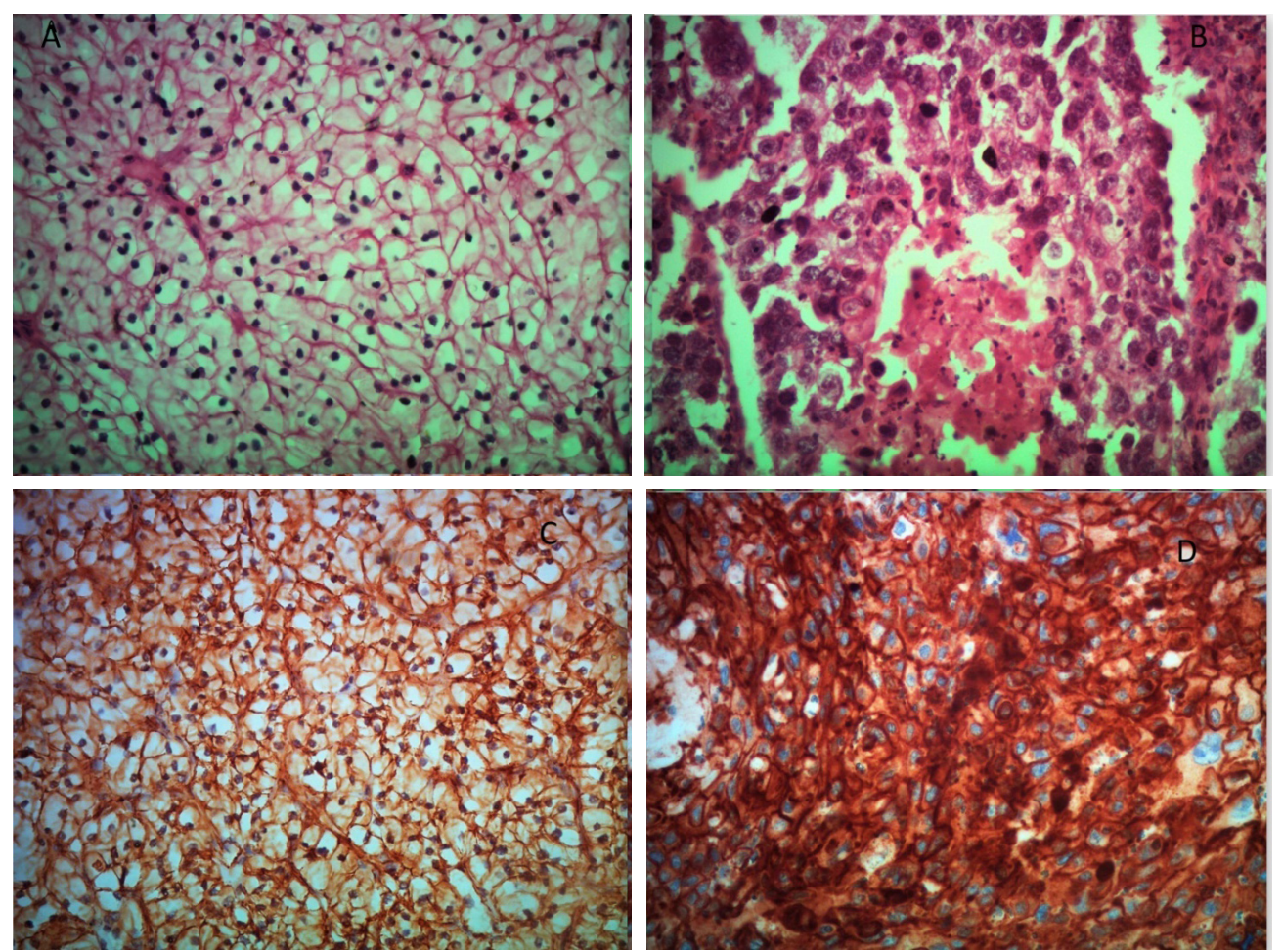

Figure 1. Clear cell RCC H\&E, X400: low grade and stage (A) \& high grade and stage (B). IHC with beta-catenin (DAB, X400): predominantly membranous in low grade and stage $(\mathbf{C}) \&$ predominantly cytoplasmic with focal nuclear in high grade and stage $(\mathbf{D})$. 
Papillary and chromophobe RCC showed predominantly cytoplasmic beta-catenin expression whereas mucinous tubular and spindle cell carcinoma and multilocular cystic renal neoplasm of low malignant potential showed membranous beta-catenin (Figure 2 $\mathrm{A}, \mathrm{B}, \mathrm{C}$ and $\mathrm{D}$ and Figure $3 \mathrm{~A}, \mathrm{~B}, \mathrm{C}$ and $\mathrm{D})$.
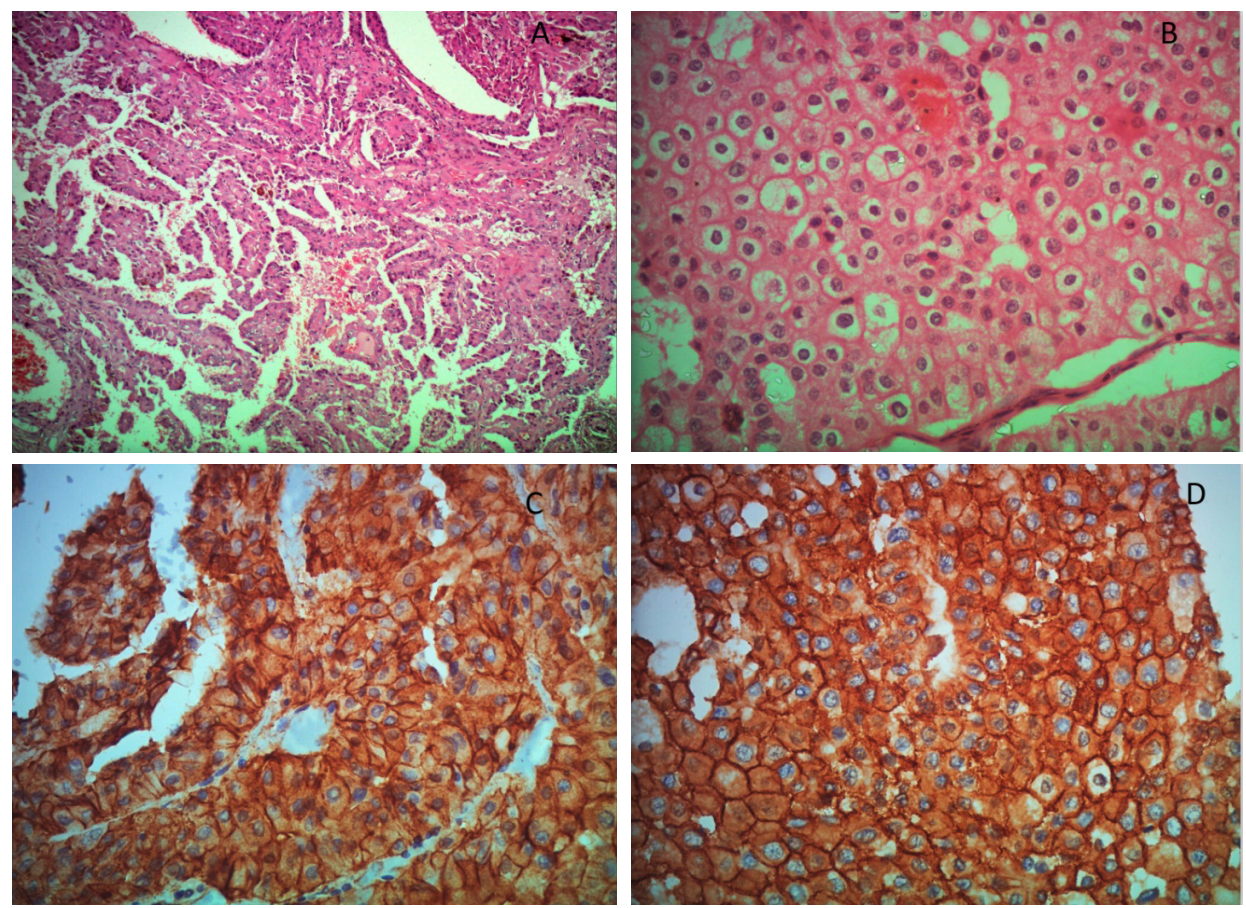

Figure 2. Papillary RCC:H\&E, X100 (A). Chromophobe RCC: H\&E, X400 (B). IHC with beta-catenin (DAB, X400): predominantly cytoplasmic in papillary (C) \& chromophobe (D) RCC.
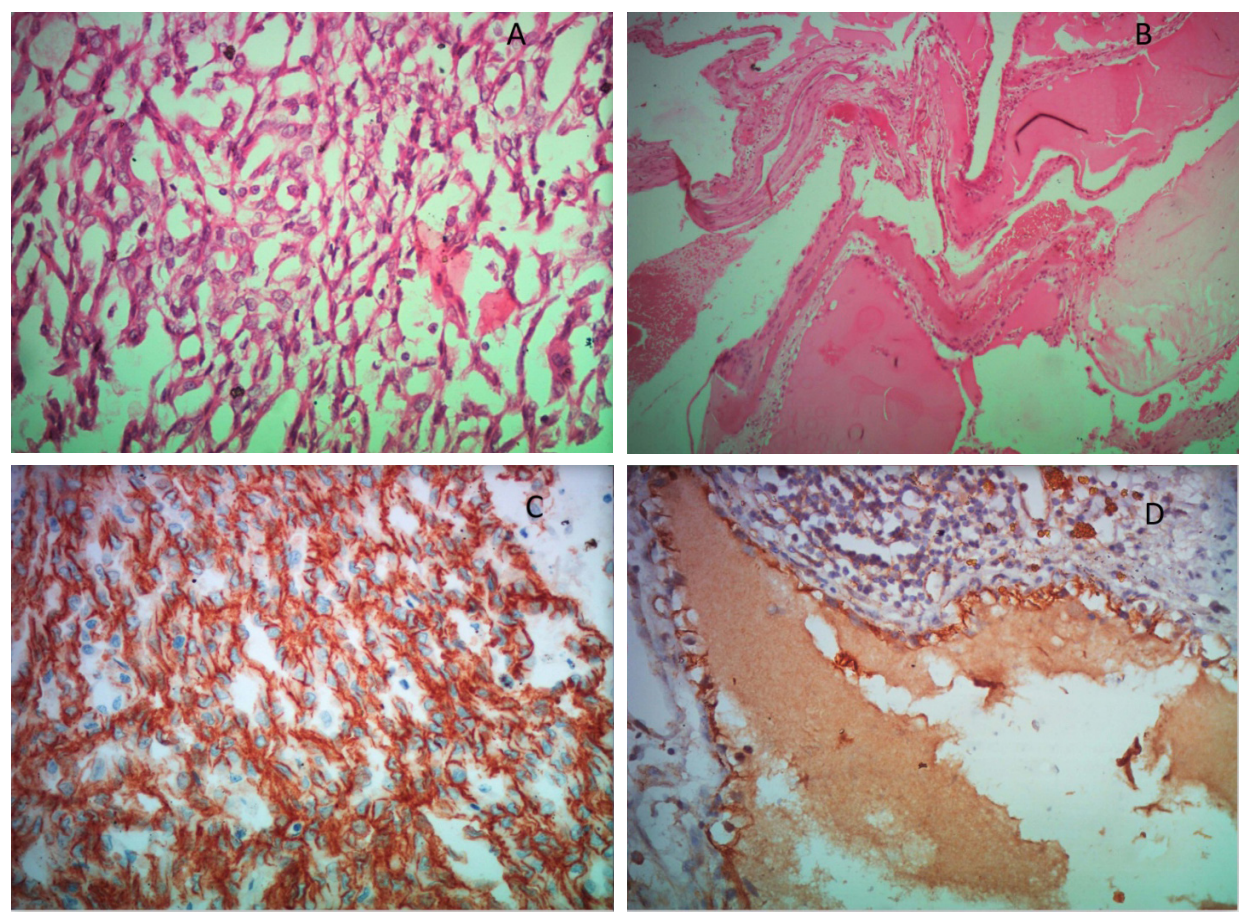

Figure 3. Mucinous tubular and spindle cell carcinoma: H\&E, X400 (A). Multilocular cystic renal neoplasm of low malignant potential: H\&E, X100 (B). IHC with beta-catenin (DAB, X400): predominantly membranous in Mucinous tubular and spindle cell carcinoma (C) $\&$ Multilocular cystic renal neoplasm of low malignant potential (D) RCC. 
Table II. Cytoplamic and membranous Scores among different types of RCC.

\begin{tabular}{|c|c|c|c|c|}
\hline Type of CA & C score Median (IQR) & p-value & M score Median (IQR) & p-value \\
\hline $\operatorname{CCRCC}(n=44)$ & $69(40-215)$ & \multirow{5}{*}{$<0.0001$} & $127(20-154.5)$ & \multirow{5}{*}{$<0.0001$} \\
\hline $\operatorname{PRCC}(\mathrm{N}=8)$ & $232(191-271.5)$ & & $28.5(5-33.5)$ & \\
\hline $\operatorname{ChRCC}(\mathrm{N}=4)$ & $262(236.5-287.5)$ & & $27.5(8.25-47.5)$ & \\
\hline $\operatorname{MTSCC}(\mathrm{N}=1)$ & 29 & & 150 & \\
\hline $\operatorname{MRNLMP}(\mathrm{N}=1)$ & 0 & & 153 & \\
\hline
\end{tabular}

Median cytoplasmic beta-catenin score was found to be lowest in clear cell (value was still lower in one single case of MTSCC), higher in papillary and highest in chromophobe RCC. Median score differences were found to be statistically significant by chi-square test for trend analysis ( $p$ value $<0.0001$ ). A similar trend was found in case of median membranous score (Table II).

There was a strong negative correlation between membranous score and tumor grade $(r=-0.787, p=<0.001)$. Mean membranous score difference between low grade (Grade 1 and 2) vs. high grade (Grade 3 and 4) was found to be statistically significant $(\mathrm{p}<0.001)$. No significant correlation was found between cytoplasmic score and tumor grade. But mean cytoplasmic score difference between low grade (grade 1 and 2) vs. high grade (grade 3 and 4) was statistically significant $(p<0.001)$ (Figure $4 a$ and $4 b$ ).
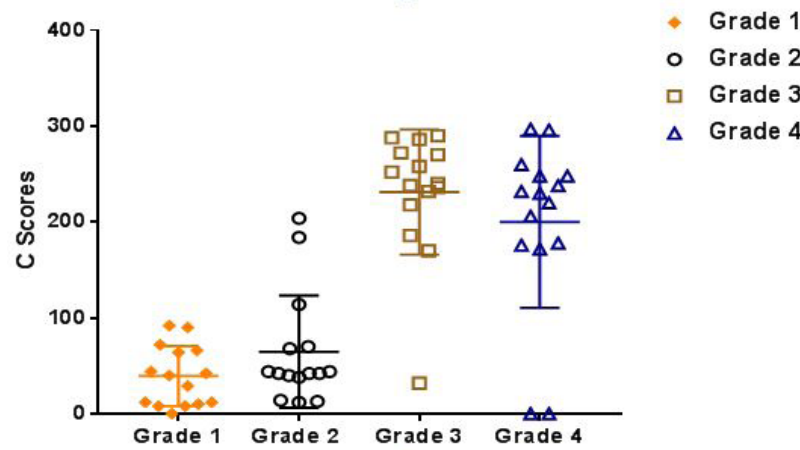

Figure 4a. Scatterplot - Membranous score vs different grades.

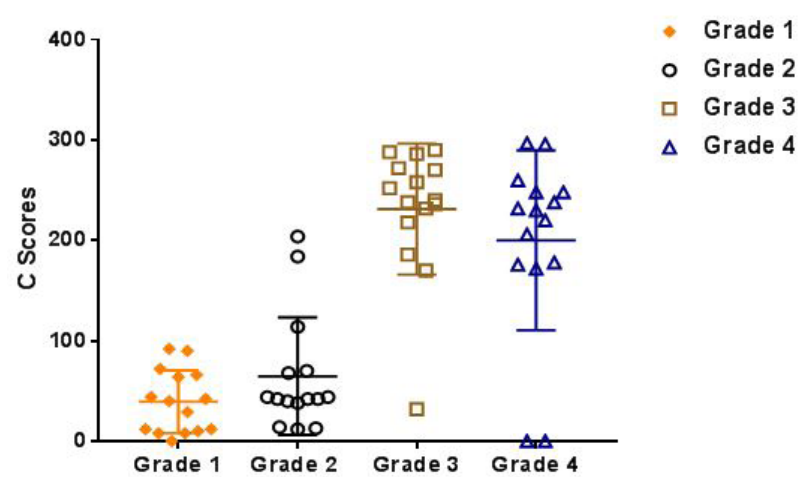

Figure 4b. Scatter plot - Cytoplasmic score vs different grades.
Both mean cytoplasmic and membranous score difference between necrosis, sarcomatoid differentiation (S/D), rhabdoid differentiation (R/D), lymphovascular invasion (LVI) and perineural invasion (PNI) present and absent cases were statistically significant $(p<0.001)$ (Figure $5 a$ and5b).

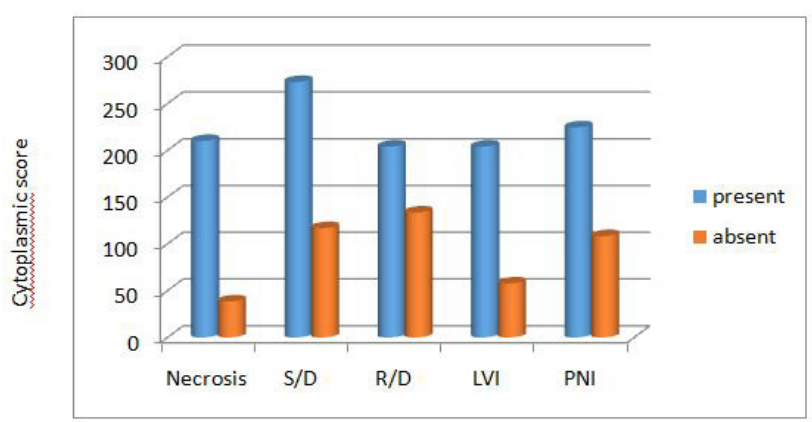

Figure 5a. Bar diagram of cytoplasmic score vs different parameters.

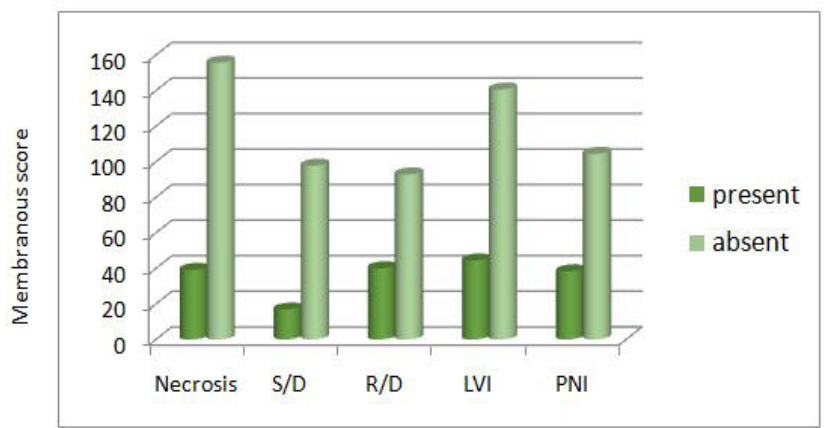

Figure 5b. Bar diagram of membranous score vs different parameters.

In the present study significant negative correlation was detected between beta-catenin membranous immunoscore ( $\mathrm{M}$ score) and stage $(\mathrm{r}=-0.407, \mathrm{p}=0.044)$. Very significant positive correlation was found between beta-catenin cytoplasmic immunoscore (C score) and stage $(\mathrm{r}=0.586 ; \mathrm{p}=0.002)$. Mean membranous and cytoplasmic score difference between low stage (Stage 1 and 2) vs. High stage (Stage 3 and 4$)$ is statistically significant $(p<0.001)$ (Figure $6 \mathrm{a}$ and $6 \mathrm{~b}$ ). 
In the present study, only 7 (12\%) cases were found to express nuclear positivity and percentage of cells show nuclear positivity was less than $10 \%$.

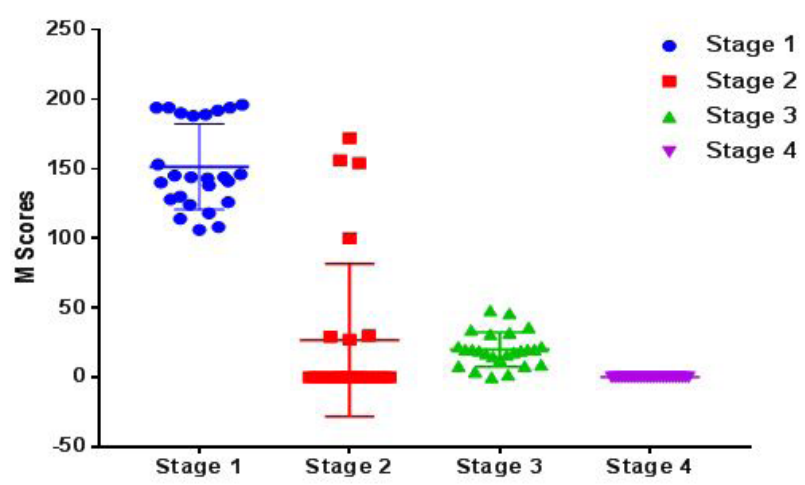

Figure 6a. Scatter plot - membranous score vs different stages.

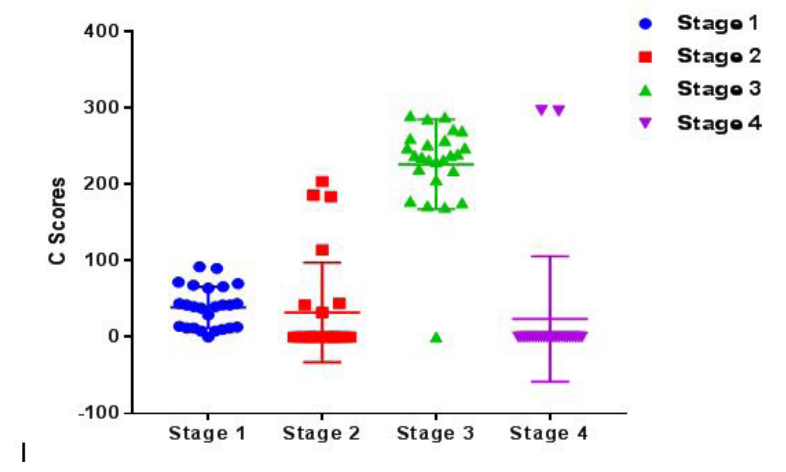

Figure 6b. Scatter plot - cytoplasmic score vs different stages.

\section{Discussion}

The most important prognostic factor of RCC is the stage of the lesion [21,22]. Tumor grade, necrosis, sarcomatoid and rhabdoid differentiation are also considered to assess the prognosis. Prognostic molecular markers add valuable information to the standard pathological variables. There is no such established molecular marker in clinical management of RCC. Such markers play a significant role in decision making, namely optimization of treatment protocol after surgery. Studies were carried out to find out the significance of beta-catenin in tumorigenesis and their quantitative and qualitative changes have been linked to tumor progression and prognosis in urological cancers [23-25]. For RCC there are contradictory reports of betacatenin expression and its association with stage, grade and other prognostic factors. No one, to our knowledge, has attempted to find out correlation between beta-catenin expression and stage and grade.

Kim et al. found cytoplasmic beta-catenin in $27 \%$ clear cell RCC case, but not in papillary and chromophobe RCC [26]. In contrast, Guo et al. observed that positive frequency and staining score of beta-catenin in papillary and chromophobe RCC was significantly higher than conventional RCC [27].

Krabbe et al. found decreased membranous and increased cytoplasmic beta-catenin expression found to be separately associated with higher pathological stage, higher Fuhrman grade and adverse pathological features including sarcomatoid differentiation, necrosis, lymphovascular invasion in clear cell RCC $(p<0.001)$ [19]. Kruck et al. had observed that in clear cell RCC high membranous beta-catenin was associated with advanced stage, vascular invasion and tumor necrosis $(\mathrm{p} \leq 0.01)$ and high cytoplasmic beta-catenin associated with higher stage and grade, vascular invasion and sarcomatoid differentiation $(\mathrm{p} \leq 0.01)$ [18]. Kovacs et al. have demonstrated that cytoplasmic expression of beta-catenin conventional RCCs significantly associated with the progression of disease from low grade to high grade $(p<0.001)$ [28]. Guo et al. had observed that in conventional RCCs the positive frequency and staining score of beta-catenin showed a significant difference between Fuhrman nuclear grades I/II and grade III $(p<0.05)$ [27]. Bilim et al. noticed that the loss of membranous betacatenin was associated with tumor stage $3\left(\mathrm{p}<0.05, \mathrm{x}^{2}=4.8\right)$ and nodal metastasis $\left(\mathrm{P} \leq 0.05, \mathrm{x}^{2}=5.86\right)$ and preserved staining associated with tumor grade $1\left(\mathrm{p}=0.005, \mathrm{x}^{2}=7.8\right)$ [17]. Aaltoma et al. noticed that weak expression intensity of beta-catenin on cell membranes was related to venous growth inside the tumor $(\mathrm{p}=0.02)$, extra tumoural venous growth $(\mathrm{p}=0.03)$ and to perineural growth $(\mathrm{p}<0.001)$ [29].

In the present study the membranous score was found to be gradually decreasing with the progression of tumor from low stage to high stage. It had a negative correlation with stage of $\mathrm{RCC}(\mathrm{r}=-0.407, \mathrm{p}=0.044)$. This observation was found to be concordant with Bilim et al. [17], Krabbe et al. [19] and discordant with Kruck et al [18]. Cytoplasmic score was found to be gradually increasing with progression of tumor from low stage to high stage. Cytoplasmic score was positively correlated with stage $(\mathrm{r}=0.586, \mathrm{p}=0.002)$. Similar findings were observed by Kruck et al. [18], Kovacs et al. [28] and Krabbe et al [19]. In the present study the membranous score was found to be gradually decreasing with the progression of tumor from low grade to high grade. It had a strong negative correlation with grade of RCC $(r=-0.787, p=<0.001)$. Krabbe et al. also found similar association with Fuhrman grading [19]. Mean cytoplasmic score difference between lower grade and higher grade was found to be statistically significant $(\mathrm{p}<0.001)$. No significant correlation was found between cytoplasmic score and tumor grade. Krabbe et al. [19], Kruck et al. [18] and Kovacs et al [28] also found association between cytoplasmic score and Fuhrman grade of RCC, but no one has further attempted to find out correlation. The small sample size may be the reason 
for which no significant correlation was found between cytoplasmic score and grade in the present study.

Both cytoplasmic and membranous score were significantly associated with prognostic parameters like necrosis, sarcomatoid differentiation, rhabdoid differentiation, lymphovascular invasion and perineural invasion $(\mathrm{p}<0.001)$. This observation was concordant with Krabbe et al [19].

It was observed that the decreased membranous expression and increased cytoplasmic expression of betacatenin were separately correlated with pathological adverse features of RCC. This observation is supported by the current understanding of the beta-catenin pathway. Staining for beta-catenin might have important implications in patients undergoing tumor biopsy before treatment decisions either in the form of radical surgery or targeted chemotherapy are undertaken. It might also help in taking decision of postoperative adjuvant therapies. In addition, this identifies beta-catenin as a potentially targetable pathway in RCC that needs further investigation.

\section{Conclusion}

Considering the observations of the current study, it can be concluded that beta-catenin may play a crucial role in the carcinogenesis of RCC. Beta-catenin has the potential to be considered as a prognostic molecular marker in the near future. Moreover, beta-Catenin, one of the main component of Wnt signaling pathway can be a critical evaluator of targeted chemotherapy in RCC. As it was a time bound study of relatively small numbers of cases with limited scope of follow up, a wider evaluation involving large number of cases provided with proper follow up facility is recommended to validate its prognostic and therapeutic efficacy.

\section{Acknowledgement}

The authors thank the head of the department of pathology Prof. (Dr.) Ranu Sarkar for her continuous support and help. We also wish to thank Dr. Soumit Dey and Dr. Debasmita Jash for providing assistance and moral support. We also wish to thank technician Pratima De for technical assistance.

\section{References}

1. Ferlay J, Soerjomataram I, Dikshit R, Eser S, Mathers C, Rebelo M, et al. Cancer incidence and mortality worldwide: sources, methods and major patterns in GLOBOCAN 2012. Int J Cancer 2015;136:E359-E386.

2. Saini S, Majid S, Dahiya R. The complex roles of Wnt antagonists in RCC. Nat Rev Urol. 2011;8:690-699.

3. Kopper L, Tímár J. Genomics of renal cell cancer-- does it provide breakthrough ? Pathol Oncol Res. 2006;12:5-11.

4. Ljungberg B, Bensalah K, Canfield S, Dabestani S, Hofmann $\mathrm{F}$, Hora $\mathrm{M}$, et al. EAU guidelines on renal cell carcinoma
2014 update. Eur Urol. 2015;67(5):913-924.

5. Singer EA, Gupta GN, Srinivasan R. Targeted therapeutic strategies for the management of renal cell carcinoma. Curr Opin Oncol. 2012;24:284-290.

6. Ho JY, Hsu RJ, Wu CL, Chang WL, Cha TL, Yu DS, et al. Ovatodiolide targets $\beta$-catenin signaling in suppressing tumorigenesis and overcoming drug resistance in renal cell carcinoma. Evid Based Complement Alternat Med. 2013;2013:161628.

7. Crispen PL, Boorjian SA, Lohse CM, Leibovich BC, Kwon ED. Predicting disease progression after nephrectomy for localized renal cell carcinoma: the utility of prognostic models and molecular biomarkers. Cancer. 2008;113:450460.

8. Volpe A, Patard JJ. Prognostic factors in renal cell carcinoma. World J Urol. 2010;28:319-327.

9. Banumathy G, Cairns P. Signaling pathways in renal cell carcinoma. Cancer Biol Ther. 2010;10:658-664.

10. Cojocaru E, Lozneanu L, Giuşcă SE, Căruntu ID, Danciu M. Renal carcinogenesis--insights into signaling pathways. Rom J Morphol Embryol. 2015;56:15-19.

11. Xu Q, Krause M, Samoylenko A, Vainio S. Wnt signaling in renal cell carcinoma. Cancers (Basel). 2016;8:57.

12. Clevers $\mathrm{H}$. Wnt/ $\beta$-catenin signaling in development and disease. Cell. 2006;127:469-480.

13. Beroukhim R, Brunet JP, Di Napoli A, Mertz KD, Seeley A, Pires MM, et al. Patterns of gene expression and copynumber alterations in von-hippel lindau disease-associated and sporadic clear cell carcinoma of the kidney. Cancer Res. 2009;69:4674-4681.

14. Furge KA, Chen J, Koeman J, Swiatek P, Dykema K, Lucin $\mathrm{K}$, et al. Detection of DNA copy number changes and oncogenic signaling abnormalities from gene expression data reveals MYC activation in high-grade papillary renal cell carcinoma. Cancer Res. 2007;67:3171-3176.

15. Monga SP, Mars WM, Pediaditakis P, Bell A, Mulé K, Bowen WC, et al. Hepatocyte growth factor induces Wnt-independent nuclear translocation of $\beta$-catenin after Met- $\beta$-catenin dissociation in hepatocytes. Cancer Res. 2002;62:2064-2071.

16. Peruzzi B, Athauda G, Bottaro DP. The von Hippel-Lindau tumor suppressor gene product represses oncogenic $\beta$-catenin signaling in renal carcinoma cells. Proc Natl Acad Sci U S A. 2006; 103:14531-14536.

17. Bilim V, Kawasaki T, Katagiri A, Wakatsuki SJ, Takahashi $\mathrm{K}$, Tomita Y. Altered expression of $\beta$-catenin in renal cell cancer and transitional cell cancer with the absence of $\beta$-catenin gene mutations. Clin Cancer Res. 2000;6:460-466.

18. Kruck S, Eyrich C, Scharpf M, Sievert KD, Fend F, Stenzl $A$, et al. Impact of an altered Wnt $1 / \beta$-catenin expression on clinicopathology and prognosis in clear cell renal cell carcinoma. Int J Mol Sci. 2013;14:10944-10957.

19. Krabbe LM, Westerman ME, Bagrodia A, Gayed BA, Darwish OM, Haddad AQ, et al. Dysregulation of $\beta$-catenin is an independent predictor of oncologic outcomes in patients with clear cell renal cell carcinoma. J Urol. 2014;191:16711677. 
20. Mauri FA, Caffo O, Veronese S, Verderio P, Boracchi $\mathrm{P}$, Bonzanini $\mathrm{M}$, et al. Tissue carcinoembryonic antigen and oestrogen receptor status in breast carcinoma: an immunohistochemical study of clinical outcome in a series of 252 patients with long-term follow-up. Br J Cancer. 1998;77:1661-1668.

21. Delahunt B, Cheville JC, Martignoni G, Humphrey PA, Magi-Galluzzi C, McKenney $\mathrm{J}$, et al. The International Society of Urological Pathology (ISUP) grading system for renal cell carcinoma and other prognostic parameters. Am J Surg Pathol. 2013;37:1490-1504.

22. Delahunt B. Advances and controversies in grading and staging of renal cell carcinoma. Mod Pathol. 2009;22 Suppl 2:S24-S36.

23. Fadare O, Reddy H, Wang J, Hileeto D, Schwartz PE, Zheng W. E-cadherin and $\beta$-catenin expression in early stage cervical carcinoma: a tissue microarray study of 147 cases. World J Surg Oncol. 2005;3:38.

24. Wong SC, Lo ES, Lee KC, Chan JK, Hsiao WW. Prognostic and diagnostic significance of $\beta$-catenin nuclear immunostaining in colorectal cancer. Clin Cancer Res. 2004;10:1401-1408.
25. Morita N, Uemura H, Tsumatani K, Cho M, Hirao Y, Okajima $\mathrm{E}$, et al. E-cadherin and $\alpha$-, $\beta$ - and $\gamma$-catenin expression in prostate cancers: correlation with tumor invasion. $\mathrm{Br} \mathrm{J}$ Cancer. 1999;79:1879-1883.

26. Kim YS, Kang YK, Kim JB, Han SA, Kim KI, Paik SR. $\beta$-Catenin expression and mutational analysis in renal cell carcinomas. Pathol Int. 2000;50:725-730.

27. Guo L, Kuroda N, Miyazaki E, Hayashi Y, Toi M, Naruse $\mathrm{K}$, et al. The complementary role of $\beta$-catenin in diagnosing various subtypes of renal cell carcinomas and its upregulation in conventional renal cell carcinomas with high nuclear grades. Oncol Rep. 2001;8:521-526.

28. Kovacs G, Billfeldt NK, Farkas N, Dergez T, Javorhazy A, Banyai D, et al. Cytoplasmic expression of $\beta$-catenin is an independent predictor of progression of conventional renal cell carcinoma: a simple immunostaining score. Histopathology. 2017;70:273-280.

29. Aaltomaa S, Lipponen P, Kärjä V, Lundstedt S, Lappi J, Kosma VM. The expression and prognostic value of $\alpha$-, $\beta$-and $\gamma$-catenins in renal cell carcinoma. Anticancer Res. 2004;24:2407-2413. 